\title{
Neurodegeneration as a consequence of failed mitochondrial maintenance
}

\author{
Mariusz Karbowski • Albert Neutzner
}

Received: 21 September 2011/Revised: 18 November 2011/ Accepted: 22 November 2011/Published online: 7 December 2011 (C) Springer-Verlag 2011

\begin{abstract}
Maintaining the functional integrity of mitochondria is pivotal for cellular survival. It appears that neuronal homeostasis depends on high-fidelity mitochondria, in particular. Consequently, mitochondrial dysfunction is a fundamental problem associated with a significant number of neurological diseases, including Parkinson's disease (PD), Huntington's disease (HD), Alzheimer's disease (AD), amyotrophic lateral sclerosis (ALS) and various peripheral neuropathies, as well as the normal aging process. To ensure optimal mitochondrial function, diverse, evolutionarily conserved mitochondrial quality control mechanisms are in place, including the scavenging of toxic reactive oxygen species (ROS) and degradation of damaged mitochondrial proteins, but also turnover of whole organelles. In this review we will discuss various mitochondriaassociated conditions, focusing on the role of protein
\end{abstract}

\section{Karbowski ( $\square)$}

Center for Biomedical Engineering and Technology and Department of Biochemistry and Molecular Biology,

University of Maryland School of Medicine,

725 W. Lombard St., Baltimore, MD 21201, USA

e-mail: mkarbowski@umaryland.edu

A. Neutzner $(\square)$

Department of Biomedicine, University of Basel,

Hebelstrasse 20, 4031 Basel, Switzerland

e-mail: albert.neutzner@unibas.ch

\section{A. Neutzner}

Department of Ophthalmology, University of Basel,

Hebelstrasse 20, 4031 Basel, Switzerland turnover in mitochondrial maintenance with special emphasis on neurodegenerative disorders.

\section{Introduction}

The involvement of mitochondria and their dysfunction in the pathogenic context of neurological disorders has been extensively debated and is now generally accepted [23, 110]. While mitochondria have long been known for their role in ATP generation through oxidative phosphorylation (OxPhos), many more diverse (patho)physiological roles for these organelles have been described during the last two decades. The traditional view of mitochondria as powerhouses quietly lingering around/resting in the cytosol of cells is now replaced by the perspective of a dynamic mitochondrial network that not only physically connects remote cellular compartments (such as neuronal synapses) to the soma but which is also intrinsically involved in major cellular life and death decisions [99, 129]. Beyond ATP generation, mitochondria are also involved in a number of critical pathways, including the buffering of calcium ions [89], lipid metabolism [35], the synthesis of iron-sulfur clusters [105], and the regulation of programmed cell death [137].

This deep integration of mitochondria into cellular physiology is reflected by the sometimes dramatic consequences linked to mitochondrial dysfunction. Physiological aging as well as age-related diseases are frequently associated with decreased mitochondrial function. Thus, diverse maintenance mechanisms, operating to keep mitochondria in a peak functional state, are of uttermost importance to prevent mitochondrial dysfunction-linked diseases, premature aging and associated cell death. 


\section{Mitochondrial damage and neurodegeneration: targets and triggers}

\section{Overview}

Mitochondria are thought to be remnants of an ancient endosymbiotic event between an anaerobic, glycolytic eubacterium and an $\alpha$-proteo bacterium around 1.5-2 billion years ago that formed modern aerobic eukaryotic cells $[52,57,107]$. The presence of bacterial chromosome-like, circular mitochondrial DNA (mtDNA), a bacterial-type protein translation apparatus, and the double membrane similar to that found in $\alpha$-proteo bacteria still bear witness of this union. This symbiotic relationship, while obviously beneficial, comes with its own set of challenges. Whereas the mitochondrial proteome consists of at least 1,000 proteins [100], mtDNA only codes for 13 of these proteins [6]. Through mitochondrial gene-transfer to the host cell genome, the vast majority of originally $\alpha$-proteo bacterial proteins is translated in the cytosol and has to be imported into mitochondria. Since the mitochondrial electron transport chain (ETC) consists of large multi-protein complexes with their subunits encoded by both the nuclear and mitochondrial genomes, nuclear as well as mitochondrial protein expression has to be tightly coordinated to avoid the production of superfluous and potentially harmful ETC subunits. Mitochondrial DNA is organized in a large, circular, plasmid-like chromosome devoid of introns and histons, with each mitochondrial subunit harboring several hundred individual copies organized in so-called nucleoids located in the mitochondrial matrix compartment. Each nucleoid contains on average 1.4 copies of mtDNA, and although histones are not present, other proteins coat the mtDNA and seem to confer some protection [14, 78]. Since the matrix-enclosing inner mitochondrial membrane (IMM) is the site of OxPhos, mtDNA is in close vicinity to the toxic by-products of OxPhos in the form of reactive oxygen species (ROS) [18]. Although a wide variety of DNA repair mechanisms that act on mtDNA are in place [13], clonal analyses of aged cells show the expansion of large mtDNA deletion mutants in single cells causing ultimately failure of the ETC as evidenced by isolated cytochrome $c$ oxidase negative muscle fibers [48]. But DNA is not the only target for oxidative damage. Proteins are also susceptible to modification, for example carbonylation [37], rendering them inactive, thus potentially impacting proper mitochondrial function [38].

\section{Mitochondrial energy production}

The components of the ETC is responsible for the transfer of electrons from nutrients to oxygen are localized in the IMM [118]. Unlike most other cell types, neurons are unable to meet their energy needs through glycolysis alone, and therefore are particularly dependent on a highly efficient ETC [113]. Consequently, insufficient mitochondrial energy production, caused by mutations impairing OxPhos components, is linked to mitochondrial disorders such as LHON (Leber's hereditary optic neuropathy), MELAS (mitochondrial myopathy, encephalopathy, lactic acidosis, and stroke-like episodes), MERRF (myoclonic epilepsy with ragged red fibers), Kearns-Sayre syndrome or CPEO (chronic progressive external ophthalmoplegia). These diseases manifest themselves with neurological symptoms such as loss of vision, deafness, ataxia, seizures, external ophthalmoplegia, and cognitive impairment, but also muscle weakness [20, 21, 29, 87]. However, mutations directly affecting mitochondrial energy production (mostly mtDNA mutations) comprise a relatively small number of neurodegenerative diseases. This is in contrast to the large number of patients affected with sporadic, late-onset neurodegenerative disorders such as Parkinson's (PD), Alzheimer's (AD) or Huntington's disease (HD). Although failure of mitochondrial energy production is associated with late-onset neurodegenerative diseases, it is still under debate whether diminished mitochondrial function is the primary cause of the disease. It is possible that subtle disturbances in mitochondrial maintenance and/or (protein) quality control, perhaps induced by dysfunctions in other cellular pathways, may over extended periods of time result in the accumulation of low-fidelity mitochondria unable to maintain sufficient ATP levels, thus leading to neuronal cell degeneration.

\section{Oxidative stress}

Closely linked to mitochondrial energy production, oxidative stress caused by mitochondrial reactive oxygen production (ROS) is often considered an underlying cause of neurodegeneration [81]. Mitochondria consume large amounts of oxygen during oxidative phosphorylation. Leakage of electrons from the ETC results in the generation of superoxide anions $\left(\mathrm{O}_{2}^{-}\right)$and, consequently, in ROS such as hydrogen peroxide or hydroxyl radicals [18]. These highly reactive species are capable of damaging proteins, membrane lipids, and DNA. Since the generation of $\mathrm{O}_{2}^{-}$ during OxPhos appears to be unavoidable and is quasi an occupational hazard for mitochondria, several defense mechanisms, including ROS scavengers and ROS converting enzymes, are in place to deal with free radicals [117] and damaged proteins or DNA, respectively [13, 122]. It is estimated that up to $2 \%$ of all electrons trafficked through the ETC are transferred prematurely to oxygen in one-electron reduction reactions causing the formation of superoxide $\left(\mathrm{O}_{2}^{-}\right)$in a process called electron leakage [18], although this value might be much lower in properly 
functioning mitochondria in vivo. Oxidative stress occurs after the antioxidant defense is overwhelmed and damage to proteins and DNA occurs. A sub-par working ETC now is a major source of electrons available for transfer to molecular oxygen [125] and an already damaged ETC might incur even more oxidative damage causing a vicious cycle that results in even more ROS production [7]. In addition, under this scenario, oxidatively damaged mtDNA would increase generation of mutated ETC components, thus further increasing ROS production. This hypothesis was first formulated by Harman [61] and ultimately led to the free radical theory of aging in the mid-fifties. However, this "vicious cycle" hypothesis has recently been challenged [124], and it is unclear to what degree mitochondrial ROS can cause sufficient mtDNA damage to impact the ETC in such a way that electron leakage is increased [53]. Interestingly, single cell analyses of mtDNA mutations revealed that individual cells contain one particular mtDNA mutation (instead of various random mutations) independently of the mutations found in neighboring cells in aged tissue [17, 48]. In addition, although the so called "mutator mouse" with an increased mtDNA mutation rate did show signs of premature aging, no elevated levels of ROS or oxidative damage were observed [124]. While these observations would argue against the "vicious cycle" hypothesis, it would support aging through accumulated mtDNA damage. Nonetheless, under certain conditions, increased ROS production is linked to neurodegeneration as exemplified below.

Friedreich's ataxia (FA), caused by mutations in the gene coding for the mitochondrial protein frataxin [19], is an example of a neurodegenerative disorder linked to increased oxidative stress and ROS production [75]. Acting as a chaperone in mitochondrial iron transport, frataxin serves important functions in the biogenesis of iron-sulfur clusters essential for ETC and tricarboxylic cycle function [102]. In patients afflicted with Friedreich's ataxia, silencing mutations result in decreased frataxin activity, causing the accumulation of $\mathrm{Fe}(\mathrm{II})$ in mitochondria, which in turn leads to increased ROS production. Interestingly, treatment of early stage FA patients with idebenone, an analog of the ETC component coenzyme Q10 results in an alleviation of neurological symptoms [56]. Another prominent link between increased ROS production and neurodegeneration is exemplified by toxins such as 1-methyl-4-phenyl-1,2,3,6-tetrahydropyridine (MPTP), the herbicide paraquat, or the pesticide rotenone, all known inhibitors of ETC complex I. While there is still insufficient epidemiological data linking, e.g., chronic paraquat exposure to neurodegeneration associated with $\mathrm{PD}$, acute exposure to MPTP causes PD-like symptoms in humans. In addition, these complex I inhibitors are widely used in inducible PD models in rodents [11].
In addition to the above-discussed conditions of $\mathrm{PD}$ and FA, Leber's hereditary optic neuropathy (LHON) impressively highlights the link between energy production, oxidative stress and neurodegeneration. LHON, occurring at a prevalence of up to 1:20,000 in certain areas of Europe, is usually caused by one of three mutations in subunits within the NADH dehydrogenase (ETC complex I) [123]. The disease exhibits a maternal inheritance as expected from mtDNA-based disease mutations. In addition, LHON exhibits a strong male bias at a low penetration (up to 50\% in males; around $10 \%$ in females) whose basis is still unclear [123]. Interestingly, the mitochondrial DNAhaplogroup background seems to influence the clinical expression of LHON mutations [65]. In most cases, LHON occurs isolated to the optic nerve, with only a small subgroup of patients displaying a plus-phenotype with additional neurological symptoms such as cerebellar ataxia or encephalomyopathy [58, 88, 95]. Intriguingly, depending on the underlying disease causing mtDNA mutation, some patients experience partial vision recovery even several years after disease onset [2]. Why LHON affects both eyes simultaneously (or over a short period of time) in mostly young, male adults is not clear. Although analyses of cells harboring LHON mutations did reveal a reduction of the respiratory capacity in the case of phenotypically more severe mutations, ROS production seemed elevated in LHON cells, independently of the underlying mutation [138]. In addition, the pronounced male bias and the sudden, mostly bilateral onset suggest additional genetic but also environmental factors. Indeed, a role for smoking in triggering LHON onset was found [74], supporting the notion that excess ROS production may be an important factor in LHON pathogenesis. This notion gains further support by the fact that antioxidant treatment may shorten the interval between disease onset and potential vision recovery [85], although final proof for such treatment of LHON is still not available [9].

\section{Misfolded proteins}

It is well established that in various neurodegenerative diseases, misfolded proteins [e.g., mutated superoxide dismutase in amyotrophic lateral sclerosis (ALS), mutant huntingtin in $\mathrm{HD}$ or $\beta$-amyloid peptide in $\mathrm{AD}$ ] accumulate on mitochondria and cause the functional decline of these organelles [47, 50, 80, 109, 128]. Recent evidence indicates that accumulation of misfolded proteins on mitochondria can lead to various functional defects of these organelles, including inhibition of mitochondrial fusion, bioenergetic defects as well as abnormal apoptosis $[47,49,50,109,130]$. Interestingly, the evidence indicates that mitochondrial accumulation of ALS-linked mutant superoxide dismutase 1 (mSOD1) leads to dramatic changes in the proteome of 
spinal cord mitochondria [80]. ALS exhibits fast progressing muscle weakness caused by the degeneration of upper and lower motor neurons. It has been found that upon exposure to $\mathrm{mSOD} 1$, levels of $\sim 50$ mitochondrial proteins, including several ETC components, as well as mitochondrial fusion factor Mfn2 were altered, indicating a possible widespread effect of mSOD1 on mitochondrial function. Furthermore, although observed decreases in some of the mitochondrial proteins were attributed to mSOD1-induced inhibition of mitochondrial protein import, increases in the levels of several other proteins were also detected. It is tempting to speculate that accumulation of "foreign" toxic proteins on the surface of mitochondria might also affect mitochondrial protein turnover, leading to further disturbances in mitochondrial proteostasis.

PD-causing misfolded $\alpha$-synuclein mutants-that like mSOD1 have also been shown to associate with the cytoplasmic site of the OMM and to induce mitochondrial dysfunctions [90] — did not affect spinal cord mitochondria in a similar to mSOD1 fashion. Thus, the question remains of how disease-linked mutant proteins effect mitochondrial function. However, alternative mechanisms underlying mSOD1-induced mitochondrial toxicity, including inhibition of the voltage-dependent anion channel (VDAC), activation of apoptosis, as well as ETC impairments, have also been described for other mitochondria-toxic proteins, including mutant huntingtin and $\alpha$-synuclein mutant $[47$, 49, 50, 69, 109, 130] suggesting a common pathogenic theme involving mitochondria. Further extending the complexity of misfolded protein-induced mitochondrial defects, a number of reports indicate that mitochondrial fusion and fission are also affected by the exposure to these toxic factors $[90,112,115,128,130,131]$. Importantly, either physical interaction with proteins implicated in mitochondrial fusion or fission or direct association with the OMM appears to be important for mitochondrial dynamics impairment by mutant huntingtin $[112,115$, 130], $\alpha$-synuclein [90], $\beta$-amyloid [131] and mSOD1 [128], indicating a close relationship between misfolded proteininduced mitochondrial dysfunction and mitochondrial fusion and fission machineries [36]. To sum up, although the data strongly suggest that mitochondrial activity is directly affected by abnormal accumulation of neurodegeneration-linked mutant proteins, the precise scenario of the events, including primary triggers and the extent to which mitochondrial defects contribute to disease pathogenesis remain to be established.

\section{Degradation of mitochondrial proteins}

Maintenance of mitochondrial proteostasis is best perceived as a three-tiered mechanism [122] (Fig. 1). Through

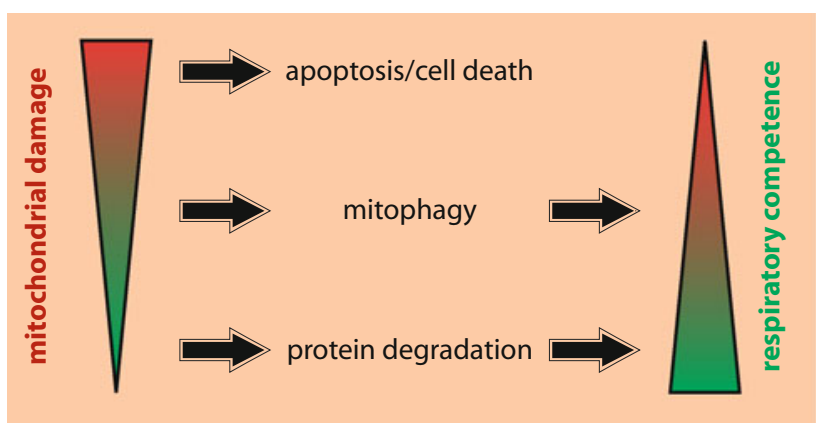

Fig. 1 Mitochondrial quality control. Several mechanisms are in place to prevent runaway mitochondrial damage in order to maintain respiratory competence. Continuous removal of damaged proteins paired with the autophagic digestion of non-functional mitochondrial subunits uphold overall mitochondrial respiration. Extensive mitochondrial damage leads to the removal of the entire mitochondrial network through programmed cell death, thus conserving overall fidelity of the host organism

the first mechanism, damaged mitochondrial networks and cells hosting them are removed by the induction of apoptotic cell death pathways [79]. The second tier is represented by the intracellular recycling/elimination of entire dysfunctional mitochondria through mitophagy, a mitochondria-specific form of autophagy $[1,73]$, with the underlying molecular pathways being discussed in the context of neurodegenerative disorders in the accompanying article by Winklhofer (this issue). Another mechanism of mitochondrial protein quality control—targeted protein degradation or proteolytic processing of mitochondrial proteins and its connection to neurological disorders-will be covered in this review. It should be pointed out, though, that these three levels of mitochondrial quality control do not act autonomously, but are instead tightly linked to basic physiological processes including mitochondrial morphology regulation.

To maintain cellular and mitochondrial homeostasis, adjusting the protein inventory to cellular needs and removing superfluous and damaged proteins is essential. Several protein processing and degradation mechanisms are in place to perform protein quality control and ensure proper mitochondrial function (Fig. 2).

\section{Protein degradation in the mitochondrial matrix}

The mitochondrial matrix is the site of the citric acid (Krebs) cycle responsible for generating reduction equivalents for use in the ETC across the IMM. Thus, protein quality control in the matrix is crucial for maintaining mitochondrial ATP production. Due to the close proximity of matrix components to the ROS producing complexes of the ETC, major oxidative damage to matrix resident proteins can occur. The enzyme aconitase, responsible for the conversion of citrate via $c i s$-aconitate to iso-citrate in the 


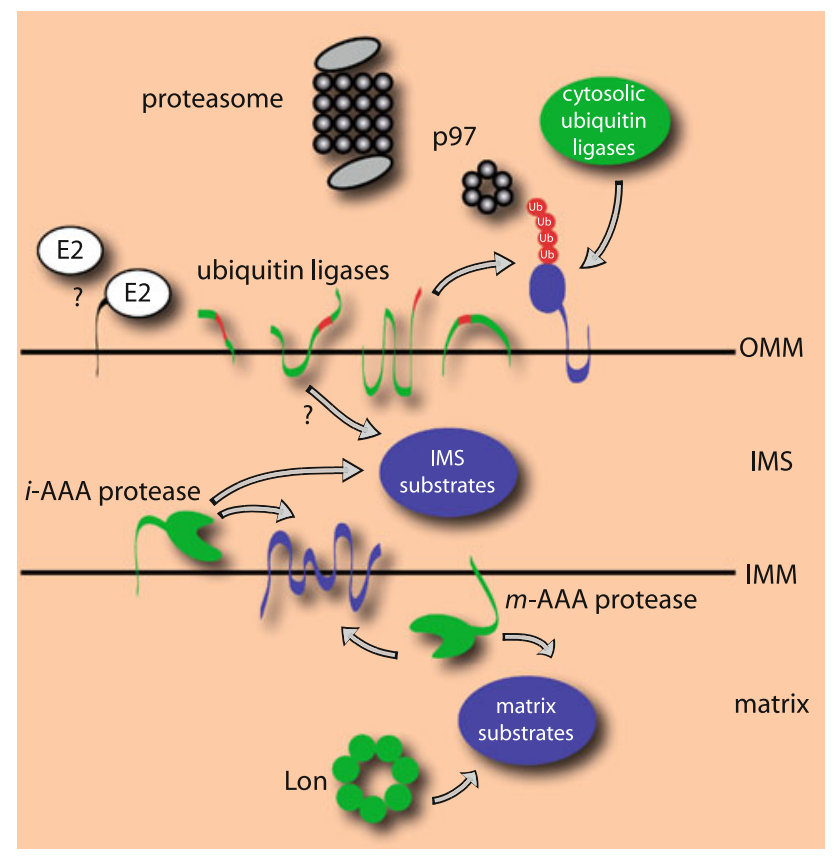

Fig. 2 Mitochondrial protein quality control. Each of the four mitochondrial compartments is under the surveillance of proteolytic machineries. Mitochondrial matrix proteins are degraded by bacterialtype Lon protease and by proteases anchored to the IMM. Proteases of the AAA-type, anchored inside the IMM and facing the matrix and the IMS compartment are responsible for degradation of membraneanchored proteins of the IMM, the matrix as well as the IMS. OMManchored ubiquitin ligases cause the degradation of OMM and potentially IMS localized proteins through a process termed OMMAD

Krebs cycle, is especially prone to oxidative damage. This is due to the presence of an iron-sulfur cluster in the active center of aconitase making this enzyme sensitive to inactivation by reactive oxygen.

Stemming from the endosymbiotic origin of mitochondria, quality control in the matrix is performed by specialized, bacterial-type proteases, namely Lon and ClpX [122]. Lon belongs to the family of AAA + ATPases and forms homomeric complexes enclosing a proteolytic chamber analogous to cytosolic proteasomes. Lon is implicated in the clearance of oxidized, carbonylated proteins from the mitochondrial matrix with inactivated aconitase being a major substrate [94]. In several aging models, an age-dependent decrease in Lon activity was found [15]. Loss of Lon activity over time causes the accumulation of damaged aconitase, thus severely impacting mitochondrial energy production. Interestingly, overexpression of Lon in a fungal aging model caused considerable healthspan extension accompanied by an increased resistance to oxidative stress and a decrease in carbonylated aconitase [83]. To date, no distinct neurodegenerative disorder is connected to Lon. However, it is tempting to speculate that a loss of Lon activity, and thus a decline in mitochondrial health during aging, might be a contributing or modifying factor triggering neurodegenerative processes. Mitochondria already under stress due to mutational alteration of key factors might depend on Lon protease activity to buffer against mitochondrial dysfunction during preclinical stages of neurodegenerative disorders.

\section{Ubiquitin-dependent degradation of mitochondrial proteins}

While mitochondrial protein turnover was long thought to be the domain of intramitochondrial specialized proteases, a role for the ubiquitin (Ub)-proteasome system (UPS) in maintaining mitochondrial function is now generally accepted [82]. The attachment of the small protein Ub to proteins, ubiquitination, is a versatile regulatory signal. Ubiquitination is a three-tiered process involving the action of Ub-activating (E1) and Ub-conjugating enzyme (E2s), and finally, Ub ligases (E3s), which confer substrate specificity to the final $\mathrm{Ub}$ transfer [32]. In most cases, ubiquitination enables, as well as causes, the recognition and subsequent proteolytic degradation of substrate proteins by the proteasome, a large cytosolic protease complex. The mitochondrial matrix, intermembrane space and IMM are devoid of ubiquitination machinery; however, several recently identified E3 Ub ligases residing in the OMM target mitochondrial proteins for $\mathrm{Ub}$ and proteasome-dependent degradation [71, 93]. In addition to the OMM-anchored E3s, soluble cytosolic Ub ligases such as Parkin (in-depth discussion by Winklhofer in the same issue) also act on mitochondrial proteins [72].

Analogous to the endoplasmic reticulum (ER), where damaged, misfolded or superfluous proteins are cleared through the ER-associated degradation (ERAD) pathway, mitochondrial proteins are under the surveillance of the OMM-associated degradation (OMMAD) pathway [93]. Ub ligases currently known to play a role in mitochondrial maintenance are the RING finger proteins MARCH5/ MITOL, MULAN, RTM9 (our unpublished observation) as well as in-between-RING-proteins IBRDC2 and Parkin $[10,16,71,121,140]$. There are striking parallels between the ER and mitochondria in terms of their molecular machineries for Ub-dependent protein degradation. Both the mitochondria and the ER harbor membrane-anchored RING finger Ub ligases facing the cytosol in a position to engage the UPS localized in the cytoplasm. The interiors of both organelles are devoid of ubiquitination machinery as well as proteasomes. In addition, the ERAD and the OMMAD pathways depend on the action of p97/valosincontaining protein (VCP). It was recently shown that p97 is involved in the retrotranslocation of ubiquitinated proteins from mitochondria [135]. The AAA-ATPase p97 forms hexameric rings which provide the necessary energy to extract ubiquitinated proteins from or transport them across 
membranes for proteasomal degradation [26]. Interestingly, mutations in p97 were found to be causative for inclusion body myopathy with Paget disease of bone and frontotemporal dementia (IBMPFD), pointing to an important role of p97 in neuronal survival [64, 132]. While ERAD is a well-studied protein degradation mechanism, research into the OMMAD pathway and its role in mitochondrial protein quality control is still in its infancy. Interestingly, certain neurodegenerative disorders are linked to failed clearance of proteins from mitochondria. ALS might be influenced by the OMMAD Ub ligase MARCH5 [136] and mutated superoxide dismutase 1 (mSOD1) has been linked to some forms of familial ALS. Mislocalization of mSOD1 to mitochondria seems to be a key factor for some of the familial forms of ALS [69, 80, 128]. While there is still controversy about the mechanism by which mSOD1 exerts its deleterious effects, MARCH5 was recently shown to cause the degradation of mSOD1, while MARCH5 knockdown by RNAi caused the stabilization of mSOD1 thus exacerbating cellular damage [136].

Besides its role in the degradation of mSOD1, MARCH5 is also involved in blunting polyQ toxicity. Expansion of a polyQ track in ataxin-3 causes Machado-Joseph (MJD), a neurological disease with late onset characterized by ataxia. It was recently shown that expression of MARCH5 reduces the accumulation of polyQ in mitochondria by inducing its ubiquitination and subsequent proteasomal degradation. Furthermore, knockdown of MARCH5 induced polyQ aggregate formation subsequently causing cytochrome $\mathrm{c}$ release and cell death [119]. However, MARCH5 is not only involved in the quality control of mutated proteins localized to mitochondria. Mitochondrial fission is also impacted by MARCH5 through increased recruitment of the fission protein Drp1 to mitochondrial scission sites following MARCH5 mutant expression [71]. Thus, MARCH5 seems to integrate two distinct mitochondrial quality control mechanisms: Ub-dependent protein degradation and maintenance of mitochondrial dynamics.

While MARCH5 is the first identified and best studied mitochondrial Ub ligase, other on mitochondria acting E3 $\mathrm{Ub}$ ligases were recently described. One of these mitochondrial Ub ligases, IBRDC2 [10], belongs to the class of in-between-ring RING finger proteins characterized by a RING finger domain flanked on both sides by additional RING fingers. IBRDC2 was recently found to be involved in the regulation of Bax-dependent programmed cell death [10]. This puts IBRDC2 in the pathway of mitochondrial quality control on the cellular level. Although no direct connection between IBRDC2 and mitochondrial dysfunction during neurodegeneration has been established to date, the involvement of this Ub ligase in apoptosis regulation makes this protein an interesting candidate and target for further studies.
A third E3 enzyme found to be integral to the OMM is MAPL/GIDE/MULAN (will be referred to as MAPL thereafter). MAPL was reported to promote ubiquitination as well as sumoylation of substrate proteins. MAPL is involved in NF- $\mathrm{KB}$ signaling and regulation of mitochondrial fission through the sumoylation of Drp1 [16], as well as programmed cell death [140]. In addition, MAPL was found to regulate a novel vesicle-based, cargo-selective transport route between mitochondria and peroxisomes [91].

The study of mitochondrial ubiquitin ligases and the degradation pathways governed by them is still in its infancy. Further research is needed to evaluate the molecular mechanisms and general importance of these proteins in maintaining mitochondrial function.

\section{Protein processing and degradation on the IMM}

The well-established connections between protein degradation and/or processing on the inner mitochondrial membrane IMM and neurodegeneration highlight the importance of protein quality control on this protein-richest cellular membrane. Mitochondrial protein turnover and processing on the IMM rely on specialized membrane-anchored proteases part of a highly conserved family of AAA proteases and evolutionary akin to the bacterial FtsH protease [84]. These proteins are the IMS-facing $i$-AAA and the matrix-facing $m$-AAA proteases. In mammals, the $i$-AAA protease is composed of homo-oligomeric hexameric complexes formed by YME1L. In humans, $m$-AAA protease has a hexameric ring-like architecture made of either a heteromeric complex consisting of the subunits paraplegin and AFG3L2 or a homomeric complex containing only AFG3L2 subunits [55]. Notably, dysfunctions of the $m$-AAA protease have been linked to neurodegenerative diseases such as hereditary spastic paraplegia (HSP) [22] and a form of dominant spinocerebellar ataxia [42]. Autosomal dominant spinocerebellar ataxias (SCA) are a heterogeneous group of neurological diseases associated with cerebellum degeneration causing progressive gait, imbalance and limb ataxia. SCA28 associated with mutations in the AFG3L2 gene accounts for around $3 \%$ of SCA cases and is the only dominant ataxia associated with mitochondrial dysfunction so far [42]. Localization studies, where AFG3L2 was found to be highly expressed in Purkinje cells and the large neurons of the deep cerebellar nuclei, correlate the disease symptoms with an important function of AFG3L2 in these neurons. In addition, this tissue-specific expression of AFG3L2 might be due to a specific protein quality control need for highly complex neurons such as Purkinje cells, which can be provided only by high levels of AFG3L2, which might also explain the highly selective neurological damage associated with SCA28. 
The second neurological disorder involving the $m$-AAA protease is associated with autosomal recessive mutations in the SPG7 gene coding for paraplegin accounting for around 5\% of cases of HSP [22]. Progressive and cellspecific axonal degeneration is a characteristic of HSP. In its pure form, HSP is characterized by slowly progressive spasticity and weakness of the limbs, with occasional mild peripheral neuropathies [12]. Additional symptoms of HSP may include cortical and cerebellar atrophy, amyotrophy, peripheral neuropathy, optic atrophy, deafness, as well as mental retardation [106]. The involvement of paraplegin connects defective mitochondrial proteolysis and/or processing with axonal degeneration. As for the pathogenesis of the paraplegin-associated HSP, whether the processing of a specific substrate or a general proteolytic defect is responsible for the observed axonal degeneration is not entirely clear. A defect in mitochondrial ribosome assembly and thus mitochondrial protein translation was suggested based on the observation of impaired processing of MRPL32 in paraplegin-deficient mice [96]. MRPL32 is a subunit of the 70S mitochondrial ribosome and as such essential for the translation of the mtDNA-encoded subunits of the ETC. While this is an interesting potential disease mechanism, paraplegin-containing $m$-AAA protease is also involved in the processing and degradation of other proteins such as OPA1 as discussed below in a different context.

\section{Disturbed mitochondrial morphology is involved in neurodegeneration}

The mitochondrial fission and fusion machineries are deeply integrated into cellular physiology, and consequently, mutations in mitochondrial morphogens do not only result in aberrant morphology of the organelles, but are causally associated with a wide spectrum of neuropathologies.

\section{Regulation of mitochondrial dynamics}

Unlike the classical textbook picture of a static beanshaped organelle living a solitary life in the cytosol, mitochondria display a more dynamic behavior [99, 111, 133]. Most cells contain, at any given time, potentially hundreds of individual mitochondria. However, this organellar individuality is mostly short lived. Due to constantly ongoing, antagonistically acting fusion and fission events (Fig. 3), mitochondria form dynamic networks that are constantly reshaped to meet diverse cellular demands.

Two separate molecular machineries govern mitochondrial morphology and dynamics. The coordinated fusion of the OMM and IMM is achieved by the concerted action of large GTPases [33]: whereas the OMM localized

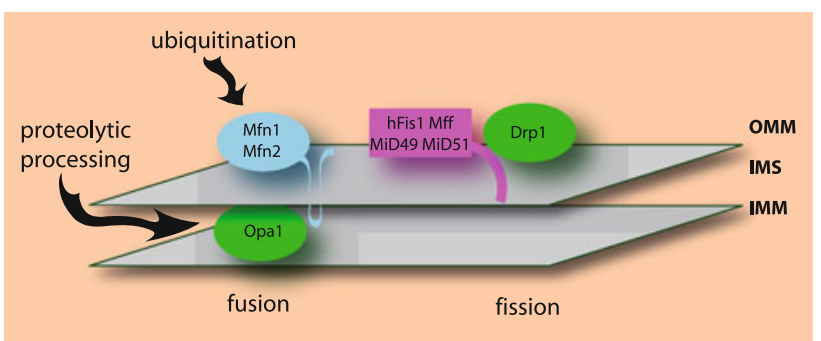

Fig. 3 Mitochondrial morphogens. Fission and fusion of mitochondria in mammalian cells are governed by large GTPases. Concerted fusion of the two mitochondrial membranes is performed by the action of the OMM localized mitofusins Mfn1 and Mfn2, and the IMM and IMS resident Opa1 protein. Mitochondria are divided by the action of the dynamin-related GTPase Drp1 after recruitment to the OMM by accessory factors. Several regulatory mechanisms are in place to shape the mitochondrial network according to cellular demand. Ubiquitin-dependent degradation of mitofusins and proteolytic processing of Opa1 modulate mitochondrial fusion rates

mitofusins Mfn1 and Mfn2 are important for organelle tethering and fusion of the OMM [77, 108], OPA1 [40], localized to the IMM and the intermembrane space, regulates fusion of the IMM. Mitochondrial fission is also governed by a large GTPase, the dynamin-related protein Drp1 [103], which is capable of forming custom-tailored spirals around mitochondria that can constrict and mediate mitochondrial division [66]. While the mitochondrial fusion proteins are membrane-bound, Drp1 is cytosolic and its mitochondrial association and activity in mammalian cells depends on various accessory proteins $[54,70,98$, 101]. Drp1 is also regulated by posttranslational modification $[16,24,25,30,63,120]$ as discussed in detail in the accompanying review by Oettinghaus and colleagues.

One can imagine the highly fused mitochondria as a system of power lines connecting the various cellular compartments, allowing for the rapid transport of energy in the form of the mitochondrial membrane potential required for a balanced production of ATP across the cell. On the other hand, fission of mitochondria produces small, mobile power units that can easily be transported to sites of high energy demand which the long, less mobile power lines cannot reach, for example neuronal synapses [68]. Through axonal transport small, highly efficient mitochondria are moved toward synapses, while inefficient or damaged mitochondria can be brought back to the soma either for repair or autophagic removal [86]. Taking this perspective, it also becomes apparent that disturbances in maintaining mitochondrial dynamics and/or transport mechanisms might severely impact cellular survival, especially that of neuronal cells [76].

The mitofusin Mfn2 and neurodegeneration

The connection between mitochondrial fission and neurodegeneration is discussed in depth by Oettinghaus and 
colleagues in the same issue. Thus, we restrict our discussion to mitochondrial fusion processes and their connection to neurodegenerative disorders. Mutations in the mitofusin Mfn2 are causally linked to the development of Charcot-Marie-Tooth disease Type 2A (CMT2A) [141]. $\mathrm{CMT}$ is a common, inherited peripheral neuropathy affecting motor as well as sensory neurons. In CMT2A, an autosomal-dominant inherited, axonal CMT subtype, the severity of the disease varies, with some patients additionally developing hearing loss and optic atrophy depending on the underlying Mfn2 mutation [31]. Interestingly, although Mfn1 and Mfn2 share significant sequence homology with each other, no connections between mutations in Mfn 1 and CMT have been reported. While it has been suggested that mutated Mfn2 acts in a dominant-negative manner [8], it is still somewhat unclear how these mutations lead to neurodegeneration. Studies on patient-derived fibroblasts carrying certain Mfn2 mutations did not reveal obvious changes in mitochondrial morphology [4]. Mfn1 can compensate for such mutations through the formation of fusion-competent heteromeric wildtype Mfn1/mutated Mfn2 complexes. Thus, tissuespecific lack of Mfn1 expression might explain the observed effect on mitochondrial morphology and disease development. Alternatively, changes in Mfn2 activity might be subtle and might manifest themselves in certain, exquisitely sensitive tissues and only after extended periods of time, as seen for some CMT2A patients with late onset and mild symptoms, where the typical manifestation age is between 10 and 50 years [31]. This notion is supported by observations made in budding yeast where only one mitofusin ortholog, Fzo1, exists: expression of Fzo1 modified to harbor equivalent pathogenic Mfn2 mutations leads to severe impairment of fusion activity, accompanied by changes in protein stability associated with such Mfn2 mutations [5]. Interestingly, mitochondrial fusion is important for maintaining respiratory competence. Complete loss of mitochondrial fusion activity through Fzo1 deletion results in loss of mtDNA and the development of a petite phenotype in yeast [104]. In mice, severe impairment of fusion through the deletion of Mfn1 or Mfn2 results in the partial loss of mtDNA in fibroblasts. In addition, aberrant mitochondrial morphology in Purkinje cells from $\mathrm{mfn}^{-/-}$mice is accompanied by impaired dendritic outgrowth and spine formation, ultimately resulting in the degeneration of these cells [27, 28]. Lastly, it should be mentioned here that Mfn2 (but not Mfn1) is also expressed on endoplasmic reticulum (ER) membranes, forming a bridge between mitochondria and the ER, essential for $\mathrm{Ca}^{2+}$ homeostasis [39, 114]. However, up to now, impaired calcium signaling due to Mfn2 mutations has not been implicated with CMT2A pathogenesis.
OPA1 processing and disease

Mitochondrial fusion is impacted on the posttranslational level by the ubiquitin-dependent turnover of mitofusin [92, 93, 121], as well as the proteolytic processing of OPA1 [45]. Furthermore, proteolytic processing of OPA1 also appears to be important for cellular and in particular neuronal homeostasis. OPA1 resides in the mitochondrial intermembrane space and is involved in IMM fusion, as well as in the regulation of mitochondrial cristae morphology [34, 79, 97]. Inhibition of OPA1 leads to spontaneous apoptosis, indicating that mitochondrial fusion and/or cristae regulation by this protein are critical for the control of mitochondrial steps in apoptosis [79, 97]. Human mitochondria contain at least eight OPA1 isoforms that arise from alternative splicing, generating OPA1 isoforms that also contain sites for proteolytic processing generating even more shorter OPA1 isoforms [41, 67]. Present in approximately equal proportions, balanced expression of long and short OPA1 isoforms is required for mitochondrial fusion [116]. The pattern of OPA1 isoforms, and, therefore, OPA1 processing, strongly depends on the functional competence of mitochondria. Consistent with this notion, the dissipation of the mitochondrial membrane potential $\left(\Delta \psi_{\mathrm{m}}\right)$, or mitochondria-targeting apoptotic stimuli induce OPA1 cleavage, the loss of long isoforms, and thus, subsequent inhibition of mitochondrial fusion $[43,59]$. The link between functional integrity of mitochondria, OPA1 processing and mitochondrial fusion suggests that proteostasis of OPA1 might be central for coordinating mitochondrial deterioration, including the dissipation of $\Delta \psi_{\mathrm{m}}$ together with the activation of mitochondrial quality control mechanisms. Indeed, it has been suggested that fusion-deficient mitochondria are separated from the dynamic network of these organelles to facilitate their efficient mitophagic removal [126].

The generation of the various OPA1 isoforms through proteolytic processing is a field of intense research. The proteolytic processing of OPA1 (Mgm1 in yeast) is a conserved process from yeast to human; however, its role and especially the proteases involved differ [84]. Most likely due to the additional roles OPA1 has acquired, especially the anti-apoptotic function, several proteases are involved in OPA1 processing in mammals. OPA1 possess three protease cleavage sites, one of which is only present after alternative splicing. While all OPA1 variants contain a recognition site for metallopeptidase for the removal of the mitochondrial targeting sequence and the m-AAA protease S1 cleavage site, OPA1 splice variants that include alternative exon $5 \mathrm{~b}$ contain an additional $i$-AAA protease $\mathrm{S} 2$ cleavage site. It was found that homo-oligomeric $m$-AAA protease isoforms containing AFG3L2 appear to be more efficient in OPA1 processing than 
paraplegin-containing isoforms of this protease [84]. However, paraplegin seems to have a role in OPA1 processing which might be crucial under certain conditions or certain tissues, e.g., neurons. Recently, OMA1, another mitochondrial protease, was linked to OPA1 processing, independently from the $m$-AAA protease during mitochondrial dysfunction $[45,62]$. The role of the rhomboidlike protease PARL in OPA1 processing, based on studies in budding yeast suggested to be a processing protease for OPA1, however, is still debated [34, 59].

OPA1 mutations are linked to about $60 \%$ of autosomal dominant optic atrophy (ADOA) cases [3, 40]; the most common inherited optic atrophy. ADOA is characterized by vision impairment resulting from loss of retinal ganglion cells. Notably, ADOA shows marked variations in clinical phenotypes and varying degrees of vision loss, even among siblings carrying identical mutations in OPA1. Thus, one might speculate that mitochondrial defects, including mtDNA mutations or abnormal mitochondrial ROS generation could serve as an additional trigger leading to optic nerve loss in OPA1 mutation-linked ADOA. Since mitochondrial oxidative phosphorylation compensation may preserve vision in patients with OPA1-linked ADOA [127], disease-linked OPA1 mutations likely affect the activity of ETC. Whether this is due to inhibition of mitochondrial fusion changes in mitochondrial cristae morphology, or a more direct effect on the ETC remains to be established. However, in contrast to OPA1 protein depletion that results in almost complete inhibition of mitochondrial fusion, ADOA-linked mutations have no or only mild effects on this process [139]. Aberrant OPA1 processing, namely decreases in long isoforms of this protein, as well as abnormal mitochondrial network organization also occur in a genetic model of premature aging (the "mutator mouse" that is expressing a proof-readingdeficient mutant of mtDNA polymerase- $\gamma$ [43]), suggesting a more common role for OPA1 in aging and disease.

The mechanisms by which lowered fusion of mitochondria and/or abnormal cristae structure could affect organelle function are not yet understood within the complex as a whole. Yet, the high rates of mitochondrial network remodeling, including fusion of these organelles, have been thought to facilitate the complementation of mtDNA. Likely, mitochondrial fusion could serve as a mechanism of mitochondrial quality control by eliminating locally concentrated defects in mitochondrial proteins by diluting them, in a similar manner as mtDNA mutations are complemented. Reciprocally, abnormally lowered fusion of mitochondria could lead to an increase in the local abundance of oxidatively modified macromolecules. Therefore, it is likely that minor defects in mitochondrial fusion might lead to partial degeneration of mitochondria in affected cells, and only cells particularly sensitive to mitochondrial dysfunction would display more severe phenotypic changes.

Interestingly, mutations of paraplegin, an $m$-AAA protease that is required for mitochondrial processing of OPA1 [67] have been linked to HSP [46, 134]. Around 5\% of cases of HSP are caused by mutations in SPG7, encoding paraplegin. In its pure form, HSP is characterized by slowly progressive spasticity and weakness of leg and hip muscles [51], with occasional mild peripheral neuropathies. As in ADOA, severity of symptoms and age of onset can vary widely, even within the same family. The link between paraplegin mutations and OPA1 processing in the development of the disease needs to be further clarified. However, a number of proteases, including YME1 [60, 116], peptidase OMA1 [45, 62], and $m$-AAA protease subunits other than paraplegin [44], can also mediate OPA1 processing, suggesting that the mechanism of OPA1 processing may vary between different cells and be regulated by distinct stimuli. Furthermore, abnormal processing of other $m$-AAA protease substrates besides OPA1 might also be critical for spastic paraplegia pathogenesis.

\section{The prevalence of optic nerve degeneration among mitochondrial disorders}

When considering mitochondrial maintenance and function in connection to neurodegenerative disorders, the very common and often most prominent involvement of the

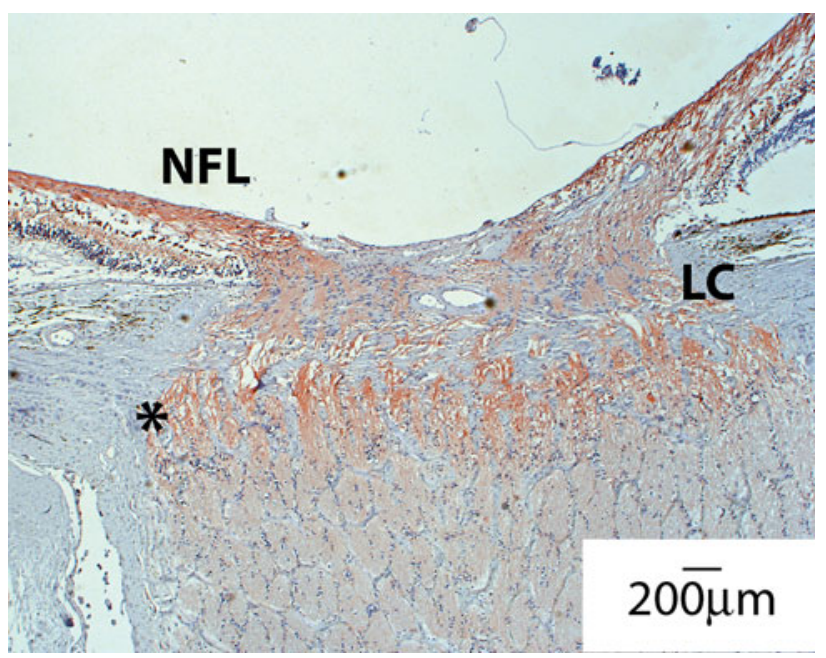

Fig. 4 Distribution of mitochondria around the optic nerve head. A section of human nerve was stained with anti-Cox 4 antibodies to assess mitochondrial distribution. Shown is the optic nerve head with the retinal layers on the top. Note the strong Cox 4 reactivity in the nerve fiber layer (NFL) before and especially after the axon left the globe (asterisk) and crossed the lamina cribrosa $(L C)$. Also note the sharp decline in mitochondrial staining along the optic nerve. This coincides with the region where myelination of the optic nerve begins 


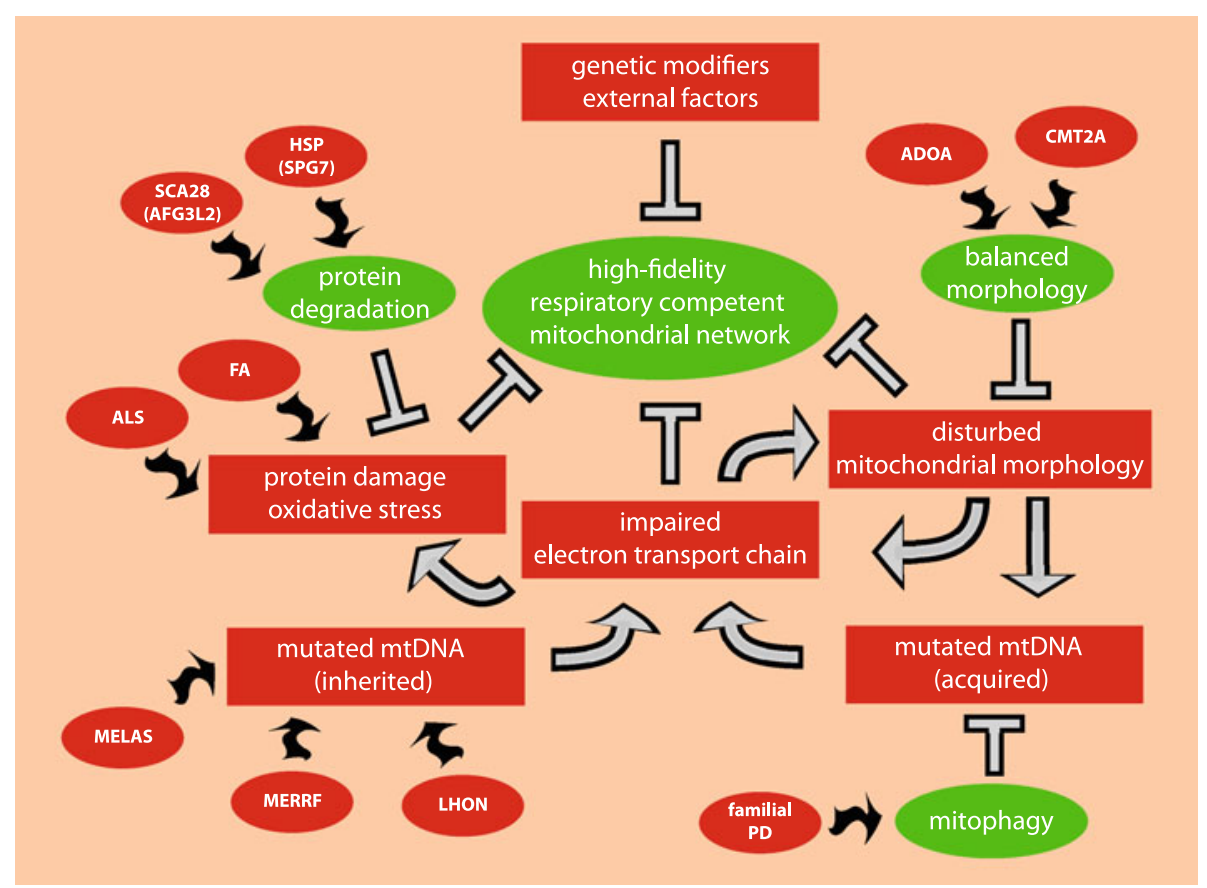

Fig. 5 Attack points of mitochondrial diseases. Protein degradation, balanced mitochondrial morphology and mitophagy promote the maintenance of a high fidelity, respiratory-competent mitochondrial network. Disturbances in mitochondrial morphology, impaired ETC through either acquired or inherited mtDNA mutations, as well as protein damage through oxidative stress cause damage to the mitochondrial network. The impact points of various neurodegenerative diseases and their direct and also indirect effects on mitochondrial health are illustrated. Mitochondrial protein degradation and processing is directly affected by disease mutations in SPG7/ paraplegin (mutated in hereditary spastic paraplegia) and AFG3L2

optic nerve is striking. LHON and ADOA are monosymptomatic and restricted to retinal ganglion cell (RGC) death. For other more complex syndromes, such as Leigh's disease, MELAS, or MERRF, vision loss due to RGC degeneration is reported [21]. In addition, careful examination of patients suffering from CMT2A and Friedreich's ataxia, as well as Mohr-Tranebjerg syndrome, revealed optic nerve involvement. Why RGCs are especially vulnerable to disturbances in mitochondrial dysfunction is still debated. Current models of optic neurodegeneration connected to mitochondrial dysfunction cite the special architecture of RGCs with mitochondria-enriched, nonmyelinated parts in the retina and the optic nerve head and comparably mitochondria-poor, myelinated tracts along the optic nerve (Fig. 4). It seems plausible to postulate that maintaining this mitochondrial gradient requires high fidelity on all levels of mitochondrial maintenance, namely fission/fusion, transport and biogenesis. In addition, compensatory mechanisms potentially active in other cell types might not be available under these circumstances. While increased mitochondrial mass may be sufficient to alleviate minor deficiencies in energy production due to mutations in (mutated in spinocerebellar ataxia). Protein damage and oxidative stress are increased in patients suffering from Friedreich's ataxia (FA) and amyotrophic lateral sclerosis (ALS). Inherited and also acquired mtDNA mutations impact the fidelity of the ETC in MELAS (mitochondrial encephalopathy, lactic acidosis, and stroke-like episodes), MERRF (myoclonic epilepsy with ragged red fibers), LHON (Leber's hereditary optic neuropathy) but also familial PD (Parkinson's disease). In addition, ETC function is indirectly affected via disturbed mitochondrial morphology in ADOA (autosomal dominant optic atrophy) as well as CMT2A (Charcott-Marie-Tooth Type 2A)

the ETC, the already high local concentration of mitochondria in the unmyelinated part of RGCs might not allow for such a mechanism.

Another interesting aspect is the often less well-defined set of clinical manifestations of the above-mentioned diseases, which often feature a remarkable phenotypic overlap. For example, carriers of OPA1 mutations might present with the classical features of ADOA but may also present with peripheral neuropathy as seen in CMT or neurological symptoms as reported for HSP patients. The same is true of LHON and ADOA. While LHON normally follows an acute course and ADOA presents as a slowly progressive optic neuropathy, certain LHON cases follow the ADOA pattern of neuropathy while there are reports of ADOA patients with acute vision loss. These findings again highlight the shared common mitochondrial dysfunctions that might manifest themselves in different ways based on other genetic or environmental modifiers (Fig. 5). In addition, these shared common features might allow generalizing findings based on the study of these different disease entities and lead to a better understanding of neurodegenerative processes. 


\section{Conclusions}

Mitochondrial dysfunction is at the heart of neurodegenerative processes. The long-held belief that defects in mitochondrial respiration are responsible for the degeneration and death of neurons during the course of most, if not all, neurodegenerative disorders is now being expanded by integrating more mitochondrial functions. While bioenergetics and associated oxidative stress are still crucial to the etiology of neurodegenerative diseases, mitochondrial protein quality control, mitochondrial dynamics and programmed cell death pathways need to be integrated for a more comprehensive understanding of the link between mitochondrial dysfunction and neurodegeneration. With the understanding of the fundamental pathogenetic mechanisms leading to neurodegeneration, a clearer picture of differences and similarities between different clinical disease entities emerges. In addition, the oftentimes striking degree of phenotypic expression of disease causing mutations and the symptomatic overlap between different diseases will likely be better understood with further acquisition of indepth knowledge of the underlying mechanisms involving mitochondrial maintenance. In the future, an even more integrative view of mitochondrial dysfunction in the context of neurodegeneration is imperative for the successful development of effective treatment strategies aimed at combating common neurodegenerative diseases.

\section{References}

1. Abeliovich H (2007) Mitophagy: the life-or-death dichotomy includes yeast. Autophagy 3(3):275-277

2. Acaroglu G, Kansu T, Dogulu CF (2001) Visual recovery patterns in children with Leber's hereditary optic neuropathy. Int Ophthalmol 24(6):349-355

3. Alexander C, Votruba M, Pesch UE, Thiselton DL, Mayer S, Moore A, Rodriguez M, Kellner U, Leo-Kottler B, Auburger G, Bhattacharya SS, Wissinger B (2000) OPA1, encoding a dynamin-related GTPase, is mutated in autosomal dominant optic atrophy linked to chromosome 3q28. Nat Genet 26(2):211-215

4. Amiott EA, Lott P, Soto J, Kang PB, McCaffery JM, DiMauro S, Abel ED, Flanigan KM, Lawson VH, Shaw JM (2008) Mitochondrial fusion and function in Charcot-Marie-Tooth type 2A patient fibroblasts with mitofusin 2 mutations. Exp Neurol 211(1):115-127

5. Amiott EA, Cohen MM, Saint-Georges Y, Weissman AM, Shaw JM (2009) A mutation associated with CMT2A neuropathy causes defects in Fzo1 GTP hydrolysis, ubiquitylation, and protein turnover. Mol Biol Cell 20(23):5026-5035

6. Anderson S, Bankier AT, Barrell BG, de Bruijn MH, Coulson AR, Drouin J, Eperon IC, Nierlich DP, Roe BA, Sanger F, Schreier PH, Smith AJ, Staden R, Young IG (1981) Sequence and organization of the human mitochondrial genome. Nature 290(5806):457-465

7. Balaban RS, Nemoto S, Finkel T (2005) Mitochondria, oxidants, and aging. Cell 120(4):483-495
8. Baloh RH, Schmidt RE, Pestronk A, Milbrandt J (2007) Altered axonal mitochondrial transport in the pathogenesis of CharcotMarie-Tooth disease from mitofusin 2 mutations. J Neurosci 27(2):422-430

9. Barnils N, Mesa E, Munoz S, Ferrer-Artola A, Arruga J (2007) Response to idebenone and multivitamin therapy in Leber's hereditary optic neuropathy. Arch Soc Esp Oftalmol 82(6): 377-380

10. Benard G, Neutzner A, Peng G, Wang C, Livak F, Youle RJ, Karbowski M (2010) IBRDC2, an IBR-type E3 ubiquitin ligase, is a regulatory factor for Bax and apoptosis activation. EMBO J 29(8):1458-1471

11. Berry C, La Vecchia C, Nicotera P (2010) Paraquat and Parkinson's disease. Cell Death Differ 17(7):1115-1125

12. Blackstone C, O'Kane CJ, Reid E (2011) Hereditary spastic paraplegias: membrane traffic and the motor pathway. Nat Rev Neurosci 12(1):31-42

13. Boesch P, Weber-Lotfi F, Ibrahim N, Tarasenko V, Cosset A, Paulus F, Lightowlers RN, Dietrich A (2011) DNA repair in organelles: Pathways, organization, regulation, relevance in disease and aging. Biochim Biophys Acta 1813(1):186-200

14. Bogenhagen DF, Rousseau D, Burke S (2008) The layered structure of human mitochondrial DNA nucleoids. J Biol Chem 283(6):3665-3675

15. Bota DA, Van Remmen H, Davies KJ (2002) Modulation of Lon protease activity and aconitase turnover during aging and oxidative stress. FEBS Lett 532(1-2):103-106

16. Braschi E, Zunino R, McBride HM (2009) MAPL is a new mitochondrial SUMO E3 ligase that regulates mitochondrial fission. EMBO Rep 10(7):748-754

17. Bua E, Johnson J, Herbst A, Delong B, McKenzie D, Salamat S, Aiken JM (2006) Mitochondrial DNA-deletion mutations accumulate intracellularly to detrimental levels in aged human skeletal muscle fibers. Am J Hum Genet 79(3):469-480

18. Cadenas E, Davies KJ (2000) Mitochondrial free radical generation, oxidative stress, and aging. Free Radic Biol Med 29(3-4):222-230

19. Campuzano V, Montermini L, Molto MD, Pianese L, Cossee M, Cavalcanti F, Monros E, Rodius F, Duclos F, Monticelli A, Zara F, Canizares J, Koutnikova H, Bidichandani SI, Gellera C, Brice A, Trouillas P, De Michele G, Filla A, De Frutos R, Palau F, Patel PI, Di Donato S, Mandel JL, Cocozza S, Koenig M, Pandolfo M (1996) Friedreich's ataxia: autosomal recessive disease caused by an intronic GAA triplet repeat expansion. Science 271(5254):1423-1427

20. Carelli V, Ross-Cisneros FN, Sadun AA (2004) Mitochondrial dysfunction as a cause of optic neuropathies. Prog Retin Eye Res 23(1):53-89

21. Carelli V, La Morgia C, Valentino ML, Barboni P, RossCisneros FN, Sadun AA (2009) Retinal ganglion cell neurodegeneration in mitochondrial inherited disorders. Biochim Biophys Acta 1787(5):518-528

22. Casari G, De Fusco M, Ciarmatori S, Zeviani M, Mora M, Fernandez P, De Michele G, Filla A, Cocozza S, Marconi R, Durr A, Fontaine B, Ballabio A (1998) Spastic paraplegia and OXPHOS impairment caused by mutations in paraplegin, a nuclear-encoded mitochondrial metalloprotease. Cell 93(6): 973-983

23. Cedarbaum JM, Blass JP (1986) Mitochondrial dysfunction and spinocerebellar degenerations. Neurochem Pathol 4(1):43-63

24. Cereghetti GM, Stangherlin A, Martins de Brito O, Chang CR, Blackstone C, Bernardi P, Scorrano L (2008) Dephosphorylation by calcineurin regulates translocation of Drp1 to mitochondria. Proc Natl Acad Sci USA 105(41):15803-15808

25. Chang CR, Blackstone C (2007) Cyclic AMP-dependent protein kinase phosphorylation of Drp1 regulates its GTPase activity 
and mitochondrial morphology. J Biol Chem 282(30):2158321587

26. Chapman E, Fry AN, Kang M (2011) The complexities of p97 function in health and disease. Mol Biosyst 7(3):700-710

27. Chen H, Detmer SA, Ewald AJ, Griffin EE, Fraser SE, Chan DC (2003) Mitofusins Mfn1 and Mfn2 coordinately regulate mitochondrial fusion and are essential for embryonic development. J Cell Biol 160(2):189-200

28. Chen H, McCaffery JM, Chan DC (2007) Mitochondrial fusion protects against neurodegeneration in the cerebellum. Cell 130(3):548-562

29. Chinnery PF, Howell N, Lightowlers RN, Turnbull DM (1997) Molecular pathology of MELAS and MERRF. The relationship between mutation load and clinical phenotypes. Brain 120(Pt 10): $1713-1721$

30. Cho DH, Nakamura T, Fang J, Cieplak P, Godzik A, Gu Z, Lipton SA (2009) S-nitrosylation of Drp1 mediates beta-amyloid-related mitochondrial fission and neuronal injury. Science 324(5923):102-105

31. Chung KW, Kim SB, Park KD, Choi KG, Lee JH, Eun HW, Suh JS, Hwang JH, Kim WK, Seo BC, Kim SH, Son IH, Kim SM, Sunwoo IN, Choi BO (2006) Early onset severe and late-onset mild Charcot-Marie-Tooth disease with mitofusin 2 (MFN2) mutations. Brain 129(Pt 8):2103-2118

32. Ciechanover A, Iwai K (2004) The ubiquitin system: from basic mechanisms to the patient bed. IUBMB Life 56(4):193-201

33. Cipolat S, Martins de Brito O, Dal Zilio B, Scorrano L (2004) OPA1 requires mitofusin 1 to promote mitochondrial fusion. Proc Natl Acad Sci USA 101(45):15927-15932

34. Cipolat S, Rudka T, Hartmann D, Costa V, Serneels L, Craessaerts K, Metzger K, Frezza C, Annaert W, D'Adamio L, Derks C, Dejaegere T, Pellegrini L, D'Hooge R, Scorrano L, De Strooper B (2006) Mitochondrial rhomboid PARL regulates cytochrome c release during apoptosis via OPA1-dependent cristae remodeling. Cell 126(1):163-175

35. Coleman RA, Lee DP (2004) Enzymes of triacylglycerol synthesis and their regulation. Prog Lipid Res 43(2):134-176

36. Costa V, Giacomello M, Hudec R, Lopreiato R, Ermak G, Lim D, Malorni W, Davies KJ, Carafoli E, Scorrano L (2010) Mitochondrial fission and cristae disruption increase the response of cell models of Huntington's disease to apoptotic stimuli. EMBO Mol Med 2(12):490-503

37. Dalle-Donne I, Rossi R, Giustarini D, Milzani A, Colombo R (2003) Protein carbonyl groups as biomarkers of oxidative stress. Clin Chim Acta 329(1-2):23-38

38. Dalle-Donne I, Aldini G, Carini M, Colombo R, Rossi R, Milzani A (2006) Protein carbonylation, cellular dysfunction, and disease progression. J Cell Mol Med 10(2):389-406

39. de Brito OM, Scorrano L (2008) Mitofusin 2 tethers endoplasmic reticulum to mitochondria. Nature 456(7222):605-610

40. Delettre C, Lenaers G, Griffoin JM, Gigarel N, Lorenzo C, Belenguer P, Pelloquin L, Grosgeorge J, Turc-Carel C, Perret E, Astarie-Dequeker C, Lasquellec L, Arnaud B, Ducommun B, Kaplan J, Hamel CP (2000) Nuclear gene OPA1, encoding a mitochondrial dynamin-related protein, is mutated in dominant optic atrophy. Nat Genet 26(2):207-210

41. Delettre C, Griffoin JM, Kaplan J, Dollfus H, Lorenz B, Faivre L, Lenaers G, Belenguer P, Hamel CP (2001) Mutation spectrum and splicing variants in the OPA1 gene. Hum Genet 109(6):584-591

42. Di Bella D, Lazzaro F, Brusco A, Plumari M, Battaglia G, Pastore A, Finardi A, Cagnoli C, Tempia F, Frontali M, Veneziano L, Sacco T, Boda E, Brussino A, Bonn F, Castellotti B, Baratta S, Mariotti C, Gellera C, Fracasso V, Magri S, Langer T, Plevani P, Di Donato S, Muzi-Falconi M, Taroni F (2010)
Mutations in the mitochondrial protease gene AFG3L2 cause dominant hereditary ataxia SCA28. Nat Genet 42(4):313-321

43. Duvezin-Caubet S, Jagasia R, Wagener J, Hofmann S, Trifunovic A, Hansson A, Chomyn A, Bauer MF, Attardi G, Larsson NG, Neupert W, Reichert AS (2006) Proteolytic processing of OPA1 links mitochondrial dysfunction to alterations in mitochondrial morphology. J Biol Chem 281(49):37972-37979

44. Duvezin-Caubet S, Koppen M, Wagener J, Zick M, Israel L, Bernacchia A, Jagasia R, Rugarli EI, Imhof A, Neupert W, Langer T, Reichert AS (2007) OPA1 processing reconstituted in yeast depends on the subunit composition of the m-AAA protease in mitochondria. Mol Biol Cell 18(9):3582-3590

45. Ehses S, Raschke I, Mancuso G, Bernacchia A, Geimer S, Tondera D, Martinou JC, Westermann B, Rugarli EI, Langer T (2009) Regulation of OPA1 processing and mitochondrial fusion by m-AAA protease isoenzymes and OMA1. J Cell Biol 187(7):1023-1036

46. Elleuch N, Depienne C, Benomar A, Hernandez AM, Ferrer X, Fontaine B, Grid D, Tallaksen CM, Zemmouri R, Stevanin G, Durr A, Brice A (2006) Mutation analysis of the paraplegin gene (SPG7) in patients with hereditary spastic paraplegia. Neurology 66(5):654-659

47. Esteves AR, Arduino DM, Silva DF, Oliveira CR, Cardoso SM (2011) Mitochondrial Dysfunction: The Road to Alpha-Synuclein Oligomerization in PD. Parkinsons Dis 2011:693761

48. Fayet G, Jansson M, Sternberg D, Moslemi AR, Blondy P, Lombes A, Fardeau M, Oldfors A (2002) Ageing muscle: clonal expansions of mitochondrial DNA point mutations and deletions cause focal impairment of mitochondrial function. Neuromuscul Disord 12(5):484-493

49. Ferreira IL, Cunha-Oliveira T, Nascimento MV, Ribeiro M, Proenca MT, Januario C, Oliveira CR, Rego AC (2011) Bioenergetic dysfunction in Huntington's disease human cybrids. Exp Neurol 231(1):127-134

50. Filosto M, Scarpelli M, Cotelli MS, Vielmi V, Todeschini A, Gregorelli V, Tonin P, Tomelleri G, Padovani A (2011) The role of mitochondria in neurodegenerative diseases. J Neurol 258(10):1763-1774

51. Fink JK, Hedera P (1999) Hereditary spastic paraplegia: genetic heterogeneity and genotype-phenotype correlation. Semin Neurol 19(3):301-309

52. Frank S, Robert EG, Youle RJ (2003) Scission, spores, and apoptosis: a proposal for the evolutionary origin of mitochondria in cell death induction. Biochem Biophys Res Commun 304(3): 481-486

53. Fukui H, Moraes CT (2008) The mitochondrial impairment, oxidative stress and neurodegeneration connection: reality or just an attractive hypothesis? Trends Neurosci 31(5):251-256

54. Gandre-Babbe S, van der Bliek AM (2008) The novel tailanchored membrane protein Mff controls mitochondrial and peroxisomal fission in mammalian cells. Mol Biol Cell 19(6):2402-2412

55. Gerdes F, Tatsuta T, Langer T (2011) Mitochondrial AAA proteases - towards a molecular understanding of membranebound proteolytic machines. Biochim Biophys Acta. doi: 10.1016/j.bbamcr.2011.09.015

56. Gille G, Reichmann H (2011) Iron-dependent functions of mitochondria-relation to neurodegeneration. J Neural Transm 118(3):349-359

57. Gray MW, Burger G, Lang BF (1999) Mitochondrial evolution. Science 283(5407):1476-1481

58. Grazina MM, Diogo LM, Garcia PC, Silva ED, Garcia TD, Robalo CB, Oliveira CR (2007) Atypical presentation of Leber's hereditary optic neuropathy associated to mtDNA $11778 \mathrm{G}>\mathrm{A}$ point mutation—a case report. Eur J Paediatr Neurol 11(2):115-118 
59. Griparic L, Kanazawa T, van der Bliek AM (2007) Regulation of the mitochondrial dynamin-like protein Opa1 by proteolytic cleavage. J Cell Biol 178(5):757-764

60. Guillery O, Malka F, Landes T, Guillou E, Blackstone C, Lombes A, Belenguer P, Arnoult D, Rojo M (2008) Metalloprotease-mediated OPA1 processing is modulated by the mitochondrial membrane potential. Biol Cell 100(5):315-325

61. Harman D (1956) Aging: a theory based on free radical and radiation chemistry. J Gerontol 11(3):298-300

62. Head B, Griparic L, Amiri M, Gandre-Babbe S, van der Bliek AM (2009) Inducible proteolytic inactivation of OPA1 mediated by the OMA1 protease in mammalian cells. J Cell Biol 187(7):959-966

63. Horn SR, Thomenius MJ, Johnson ES, Freel CD, Wu JQ, Coloff JL, Yang CS, Tang W, An J, Ilkayeva OR, Rathmell JC, Newgard CB, Kornbluth S (2011) Regulation of mitochondrial morphology by APC/CCdh1-mediated control of Drp1 stability. Mol Biol Cell 22(8):1207-1216

64. Hubbers CU, Clemen CS, Kesper K, Boddrich A, Hofmann A, Kamarainen O, Tolksdorf K, Stumpf M, Reichelt J, Roth U, Krause S, Watts G, Kimonis V, Wattjes MP, Reimann J, Thal DR, Biermann K, Evert BO, Lochmuller H, Wanker EE, Schoser BG, Noegel AA, Schroder R (2007) Pathological consequences of VCP mutations on human striated muscle. Brain 130(Pt 2):381-393

65. Hudson G, Carelli V, Spruijt L, Gerards M, Mowbray C, Achilli A, Pyle A, Elson J, Howell N, La Morgia C, Valentino ML, Huoponen K, Savontaus ML, Nikoskelainen E, Sadun AA, Salomao SR, Belfort R Jr, Griffiths P, Man PY, de Coo RF, Horvath R, Zeviani M, Smeets HJ, Torroni A, Chinnery PF (2007) Clinical expression of Leber hereditary optic neuropathy is affected by the mitochondrial DNA-haplogroup background. Am J Hum Genet 81(2):228-233

66. Ingerman E, Perkins EM, Marino M, Mears JA, McCaffery JM, Hinshaw JE, Nunnari J (2005) Dnm1 forms spirals that are structurally tailored to fit mitochondria. J Cell Biol 170(7): 1021-1027

67. Ishihara N, Fujita Y, Oka T, Mihara K (2006) Regulation of mitochondrial morphology through proteolytic cleavage of OPA1. EMBO J 25(13):2966-2977

68. Ishihara N, Nomura M, Jofuku A, Kato H, Suzuki SO, Masuda K, Otera H, Nakanishi Y, Nonaka I, Goto Y, Taguchi N, Morinaga H, Maeda M, Takayanagi R, Yokota S, Mihara K (2009) Mitochondrial fission factor Drp1 is essential for embryonic development and synapse formation in mice. Nat Cell Biol 11(8):958-966

69. Israelson A, Arbel N, Da Cruz S, Ilieva H, Yamanaka K, Shoshan-Barmatz V, Cleveland DW (2010) Misfolded mutant SOD1 directly inhibits VDAC1 conductance in a mouse model of inherited ALS. Neuron 67(4):575-587

70. James DI, Parone PA, Mattenberger Y, Martinou JC (2003) hFis1, a novel component of the mammalian mitochondrial fission machinery. J Biol Chem 278(38):36373-36379

71. Karbowski M, Neutzner A, Youle RJ (2007) The mitochondrial E3 ubiquitin ligase MARCH5 is required for Drp1 dependent mitochondrial division. J Cell Biol 178(1):71-84

72. Karbowski M, Youle RJ (2011) Regulating mitochondrial outer membrane proteins by ubiquitination and proteasomal degradation. Curr Opin Cell Biol 23(4):476-482

73. Kim I, Rodriguez-Enriquez S, Lemasters JJ (2007) Selective degradation of mitochondria by mitophagy. Arch Biochem Biophys 462(2):245-253

74. Kirkman MA, Yu-Wai-Man P, Korsten A, Leonhardt M, Dimitriadis K, De Coo IF, Klopstock T, Chinnery PF (2009) Geneenvironment interactions in Leber hereditary optic neuropathy. Brain 132(Pt 9):2317-2326
75. Klockgether T, Paulson H (2011) Milestones in ataxia. Mov Disord 26(6):1134-1141

76. Knott AB, Bossy-Wetzel E (2008) Impairing the mitochondrial fission and fusion balance: a new mechanism of neurodegeneration. Ann N Y Acad Sci 1147:283-292

77. Koshiba T, Detmer SA, Kaiser JT, Chen H, McCaffery JM, Chan DC (2004) Structural basis of mitochondrial tethering by mitofusin complexes. Science 305(5685):858-862

78. Kukat C, Wurm CA, Spahr H, Falkenberg M, Larsson NG, Jakobs S (2011) Super-resolution microscopy reveals that mammalian mitochondrial nucleoids have a uniform size and frequently contain a single copy of mtDNA. Proc Natl Acad Sci USA 108(33):13534-13539

79. Lee YJ, Jeong SY, Karbowski M, Smith CL, Youle RJ (2004) Roles of the mammalian mitochondrial fission and fusion mediators Fis1, Drp1, and Opa1 in apoptosis. Mol Biol Cell 15(11):5001-5011

80. Li Q, Vande Velde C, Israelson A, Xie J, Bailey AO, Dong MQ, Chun SJ, Roy T, Winer L, Yates JR, Capaldi RA, Cleveland DW, Miller TM (2010) ALS-linked mutant superoxide dismutase 1 (SOD1) alters mitochondrial protein composition and decreases protein import. Proc Natl Acad Sci USA 107(49):21146-21151

81. Lin MT, Beal MF (2006) Mitochondrial dysfunction and oxidative stress in neurodegenerative diseases. Nature 443(7113): 787-795

82. Livnat-Levanon N, Glickman MH (2011) Ubiquitin-proteasome system and mitochondria-reciprocity. Biochim Biophys Acta 1809(2):80-87

83. Luce K, Osiewacz HD (2009) Increasing organismal healthspan by enhancing mitochondrial protein quality control. Nat Cell Biol 11(7):852-858

84. Martinelli P, Rugarli EI (2010) Emerging roles of mitochondrial proteases in neurodegeneration. Biochim Biophys Acta 1797(1): $1-10$

85. Mashima Y, Kigasawa K, Wakakura M, Oguchi Y (2000) Do idebenone and vitamin therapy shorten the time to achieve visual recovery in Leber hereditary optic neuropathy? J Neuroophthalmol 20(3):166-170

86. Miller KE, Sheetz MP (2004) Axonal mitochondrial transport and potential are correlated. J Cell Sci 117(Pt 13):2791-2804

87. Moraes CT, DiMauro S, Zeviani M, Lombes A, Shanske S, Miranda AF, Nakase H, Bonilla E, Werneck LC, Servidei S et al (1989) Mitochondrial DNA deletions in progressive external ophthalmoplegia and Kearns-Sayre syndrome. N Engl J Med 320(20):1293-1299

88. Murakami T, Mita S, Tokunaga M, Maeda H, Ueyama H, Kumamoto T, Uchino M, Ando M (1996) Hereditary cerebellar ataxia with Leber's hereditary optic neuropathy mitochondrial DNA 11778 mutation. J Neurol Sci 142(1-2):111-113

89. Murgia M, Giorgi C, Pinton P, Rizzuto R (2009) Controlling metabolism and cell death: at the heart of mitochondrial calcium signalling. J Mol Cell Cardiol 46(6):781-788

90. Nakamura K, Nemani VM, Azarbal F, Skibinski G, Levy JM, Egami K, Munishkina L, Zhang J, Gardner B, Wakabayashi J, Sesaki H, Cheng Y, Finkbeiner S, Nussbaum RL, Masliah E, Edwards RH (2011) Direct membrane association drives mitochondrial fission by the Parkinson disease-associated protein alpha-synuclein. J Biol Chem 286(23):20710-20726

91. Neuspiel M, Schauss AC, Braschi E, Zunino R, Rippstein P, Rachubinski RA, Andrade-Navarro MA, McBride HM (2008) Cargo-selected transport from the mitochondria to peroxisomes is mediated by vesicular carriers. Curr Biol 18(2):102-108

92. Neutzner A, Youle RJ (2005) Instability of the mitofusin Fzo1 regulates mitochondrial morphology during the mating response of the yeast Saccharomyces cerevisiae. J Biol Chem 280(19): 18598-18603 
93. Neutzner A, Youle RJ, Karbowski M (2007) Outer mitochondrial membrane protein degradation by the proteasome. Novartis Found Symp 287:4-14 (discussion 14-20)

94. Ngo JK, Davies KJ (2007) Importance of the lon protease in mitochondrial maintenance and the significance of declining lon in aging. Ann N Y Acad Sci 1119:78-87

95. Nikoskelainen EK, Marttila RJ, Huoponen K, Juvonen V, Lamminen T, Sonninen P, Savontaus ML (1995) Leber's "plus": neurological abnormalities in patients with Leber's hereditary optic neuropathy. J Neurol Neurosurg Psychiatry 59(2):160-164

96. Nolden M, Ehses S, Koppen M, Bernacchia A, Rugarli EI, Langer T (2005) The m-AAA protease defective in hereditary spastic paraplegia controls ribosome assembly in mitochondria. Cell 123(2):277-289

97. Olichon A, Baricault L, Gas N, Guillou E, Valette A, Belenguer P, Lenaers G (2003) Loss of OPA1 perturbates the mitochondrial inner membrane structure and integrity, leading to cytochrome $\mathrm{c}$ release and apoptosis. J Biol Chem 278(10):77437746

98. Otera H, Wang C, Cleland MM, Setoguchi K, Yokota S, Youle RJ, Mihara K (2010) Mff is an essential factor for mitochondrial recruitment of Drp1 during mitochondrial fission in mammalian cells. J Cell Biol 191(6):1141-1158

99. Otera H, Mihara K (2011) Molecular mechanisms and physiologic functions of mitochondrial dynamics. J Biochem 149(3): 241-251

100. Pagliarini DJ, Calvo SE, Chang B, Sheth SA, Vafai SB, Ong SE, Walford GA, Sugiana C, Boneh A, Chen WK, Hill DE, Vidal M, Evans JG, Thorburn DR, Carr SA, Mootha VK (2008) A mitochondrial protein compendium elucidates complex I disease biology. Cell 134(1):112-123

101. Palmer CS, Osellame LD, Laine D, Koutsopoulos OS, Frazier AE, Ryan MT (2011) MiD49 and MiD51, new components of the mitochondrial fission machinery. EMBO Rep 12(6):565-573

102. Pandolfo M (2008) Friedreich ataxia. Arch Neurol 65(10): 1296-1303

103. Pitts KR, Yoon Y, Krueger EW, McNiven MA (1999) The dynamin-like protein DLP1 is essential for normal distribution and morphology of the endoplasmic reticulum and mitochondria in mammalian cells. Mol Biol Cell 10(12):4403-4417

104. Rapaport D, Brunner M, Neupert W, Westermann B (1998) Fzo1p is a mitochondrial outer membrane protein essential for the biogenesis of functional mitochondria in Saccharomyces cerevisiae. J Biol Chem 273(32):20150-20155

105. Rouault TA, Tong WH (2005) Iron-sulphur cluster biogenesis and mitochondrial iron homeostasis. Natl Rev Mol Cell Biol 6(4):345-351

106. Rugarli EI, Langer $\mathrm{T}$ (2006) Translating m-AAA protease function in mitochondria to hereditary spastic paraplegia. Trends Mol Med 12(6):262-269

107. Sagan L (1967) On the origin of mitosing cells. J Theor Biol 14(3):255-274

108. Santel A, Fuller MT (2001) Control of mitochondrial morphology by a human mitofusin. J Cell Sci 114(Pt 5):867-874

109. Schmidt S, Linnartz B, Mendritzki S, Sczepan T, Lubbert M, Stichel CC, Lubbert H (2011) Genetic mouse models for Parkinson's disease display severe pathology in glial cell mitochondria. Hum Mol Genet 20(6):1197-1211

110. Schon EA, Przedborski S (2011) Mitochondria: the next (neurode)generation. Neuron 70(6):1033-1053

111. Shaw JM, Nunnari J (2002) Mitochondrial dynamics and division in budding yeast. Trends Cell Biol 12(4):178-184

112. Shirendeb U, Reddy AP, Manczak M, Calkins MJ, Mao P, Tagle DA, Reddy PH (2011) Abnormal mitochondrial dynamics, mitochondrial loss and mutant huntingtin oligomers in
Huntington's disease: implications for selective neuronal damage. Hum Mol Genet 20(7):1438-1455

113. Simpson IA, Carruthers A, Vannucci SJ (2007) Supply and demand in cerebral energy metabolism: the role of nutrient transporters. J Cereb Blood Flow Metab 27(11):1766-1791

114. Singaravelu K, Nelson C, Bakowski D, de Brito OM, Ng SW, Di Capite J, Powell T, Scorrano L, Parekh AB (2011) Mitofusin 2 regulates STIM1 migration from the $\mathrm{Ca} 2+$ store to the plasma membrane in cells with depolarized mitochondria. J Biol Chem 286(14):12189-12201

115. Song W, Chen J, Petrilli A, Liot G, Klinglmayr E, Zhou Y, Poquiz P, Tjong J, Pouladi MA, Hayden MR, Masliah E, Ellisman M, Rouiller I, Schwarzenbacher R, Bossy B, Perkins G, Bossy-Wetzel E (2011) Mutant huntingtin binds the mitochondrial fission GTPase dynamin-related protein-1 and increases its enzymatic activity. Nat Med 17(3):377-382

116. Song Z, Chen H, Fiket M, Alexander C, Chan DC (2007) OPA1 processing controls mitochondrial fusion and is regulated by mRNA splicing, membrane potential, and Yme1L. J Cell Biol 178(5):749-755

117. Starkov AA (2008) The role of mitochondria in reactive oxygen species metabolism and signaling. Ann N Y Acad Sci 1147:37-52

118. Stuart RA (2008) Supercomplex organization of the oxidative phosphorylation enzymes in yeast mitochondria. J Bioenerg Biomembr 40(5):411-417

119. Sugiura A, Yonashiro R, Fukuda T, Matsushita N, Nagashima S, Inatome R, Yanagi S (2011) A mitochondrial ubiquitin ligase MITOL controls cell toxicity of polyglutamine-expanded protein. Mitochondrion 11(1):139-146

120. Taguchi N, Ishihara N, Jofuku A, Oka T, Mihara K (2007) Mitotic phosphorylation of dynamin-related GTPase Drp1 participates in mitochondrial fission. J Biol Chem 282(15):1152111529

121. Tanaka A, Cleland MM, Xu S, Narendra DP, Suen DF, Karbowski M, Youle RJ (2010) Proteasome and p97 mediate mitophagy and degradation of mitofusins induced by Parkin. J Cell Biol 191(7):1367-1380

122. Tatsuta T, Langer T (2008) Quality control of mitochondria: protection against neurodegeneration and ageing. EMBO $\mathrm{J}$ 27(2):306-314

123. Tonska K, Kodron A, Bartnik E (2010) Genotype-phenotype correlations in Leber hereditary optic neuropathy. Biochim Biophys Acta 1797(6-7):1119-1123

124. Trifunovic A, Hansson A, Wredenberg A, Rovio AT, Dufour E, Khvorostov I, Spelbrink JN, Wibom R, Jacobs HT, Larsson NG (2005) Somatic mtDNA mutations cause aging phenotypes without affecting reactive oxygen species production. Proc Natl Acad Sci USA 102(50):17993-17998

125. Turrens JF (2003) Mitochondrial formation of reactive oxygen species. J Physiol 552(Pt 2):335-344

126. Twig G, Elorza A, Molina AJ, Mohamed H, Wikstrom JD, Walzer G, Stiles L, Haigh SE, Katz S, Las G, Alroy J, Wu M, Py BF, Yuan J, Deeney JT, Corkey BE, Shirihai OS (2008) Fission and selective fusion govern mitochondrial segregation and elimination by autophagy. EMBO J 27(2):433-446

127. Van Bergen NJ, Crowston JG, Kearns LS, Staffieri SE, Hewitt AW, Cohn AC, Mackey DA, Trounce IA (2011) Mitochondrial oxidative phosphorylation compensation may preserve vision in patients with OPA1-linked autosomal dominant optic atrophy. PLoS One 6(6):e21347

128. Vande Velde C, McDonald KK, Boukhedimi Y, McAlonisDownes M, Lobsiger CS, Bel Hadj S, Zandona A, Julien JP, Shah SB, Cleveland DW (2011) Misfolded SOD1 Associated with Motor Neuron Mitochondria Alters Mitochondrial Shape and Distribution Prior to Clinical Onset. PLoS One 6(7):e22031 
129. Wang C, Youle RJ (2009) The role of mitochondria in apoptosis*. Annu Rev Genet 43:95-118

130. Wang H, Lim PJ, Karbowski M, Monteiro MJ (2009) Effects of overexpression of huntingtin proteins on mitochondrial integrity. Hum Mol Genet 18(4):737-752

131. Wang X, Su B, Siedlak SL, Moreira PI, Fujioka H, Wang Y, Casadesus G, Zhu X (2008) Amyloid-beta overproduction causes abnormal mitochondrial dynamics via differential modulation of mitochondrial fission/fusion proteins. Proc Natl Acad Sci USA 105(49):19318-19323

132. Watts GD, Wymer J, Kovach MJ, Mehta SG, Mumm S, Darvish D, Pestronk A, Whyte MP, Kimonis VE (2004) Inclusion body myopathy associated with Paget disease of bone and frontotemporal dementia is caused by mutant valosin-containing protein. Nat Genet 36(4):377-381

133. Westermann B (2008) Molecular machinery of mitochondrial fusion and fission. J Biol Chem 283(20):13501-13505

134. Wilkinson PA, Crosby AH, Turner C, Bradley LJ, Ginsberg L, Wood NW, Schapira AH, Warner TT (2004) A clinical, genetic and biochemical study of SPG7 mutations in hereditary spastic paraplegia. Brain 127(Pt 5):973-980

135. Xu S, Peng G, Wang Y, Fang S, Karbowski M (2011) The AAA-ATPase p97 is essential for outer mitochondrial membrane protein turnover. Mol Biol Cell 22(3):291-300

136. Yonashiro R, Sugiura A, Miyachi M, Fukuda T, Matsushita N, Inatome R, Ogata Y, Suzuki T, Dohmae N, Yanagi S (2009)
Mitochondrial ubiquitin ligase MITOL ubiquitinates mutant SOD1 and attenuates mutant SOD1-induced reactive oxygen species generation. Mol Biol Cell 20(21):4524-4530

137. Youle RJ, Strasser A (2008) The BCL-2 protein family: opposing activities that mediate cell death. Natl Rev Mol Cell Biol 9(1):47-59

138. Yu-Wai-Man P, Griffiths PG, Chinnery PF (2011) Mitochondrial optic neuropathies-disease mechanisms and therapeutic strategies. Prog Retin Eye Res 30(2):81-114

139. Zanna C, Ghelli A, Porcelli AM, Karbowski M, Youle RJ, Schimpf S, Wissinger B, Pinti M, Cossarizza A, Vidoni S, Valentino ML, Rugolo M, Carelli V (2008) OPA1 mutations associated with dominant optic atrophy impair oxidative phosphorylation and mitochondrial fusion. Brain 131(Pt 2):352-367

140. Zhang B, Huang J, Li HL, Liu T, Wang YY, Waterman P, Mao AP, Xu LG, Zhai Z, Liu D, Marrack P, Shu HB (2008) GIDE is a mitochondrial E3 ubiquitin ligase that induces apoptosis and slows growth. Cell Res 18(9):900-910

141. Zuchner S, Mersiyanova IV, Muglia M, Bissar-Tadmouri N, Rochelle J, Dadali EL, Zappia M, Nelis E, Patitucci A, Senderek J, Parman Y, Evgrafov O, Jonghe PD, Takahashi Y, Tsuji S, Pericak-Vance MA, Quattrone A, Battaloglu E, Polyakov AV, Timmerman V, Schroder JM, Vance JM (2004) Mutations in the mitochondrial GTPase mitofusin 2 cause Charcot-Marie-Tooth neuropathy type 2A. Nat Genet 36(5):449-451 